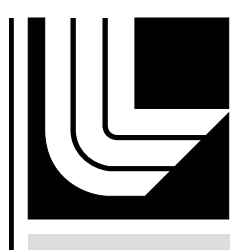

LAW RENCE LIVERMORE N A TIO N A L LABORATORY
Chemical Kinetic Models for $\mathrm{HCCl}$ and Diesel Combustion

W. J. Pitz, C. K. Westbrook, M. Mehl, S. M. Sarathy

November 16, 2010 
This document was prepared as an account of work sponsored by an agency of the United States government. Neither the United States government nor Lawrence Livermore National Security, LLC, nor any of their employees makes any warranty, expressed or implied, or assumes any legal liability or responsibility for the accuracy, completeness, or usefulness of any information, apparatus, product, or process disclosed, or represents that its use would not infringe privately owned rights. Reference herein to any specific commercial product, process, or service by trade name, trademark, manufacturer, or otherwise does not necessarily constitute or imply its endorsement, recommendation, or favoring by the United States government or Lawrence Livermore National Security, LLC. The views and opinions of authors expressed herein do not necessarily state or reflect those of the United States government or Lawrence Livermore National Security, LLC, and shall not be used for advertising or product endorsement purposes.

This work performed under the auspices of the U.S. Department of Energy by Lawrence Livermore National Laboratory under Contract DE-AC52-07NA27344. 


\section{Chemical Kinetic Models for HCCI and Diesel Combustion}

William J. Pitz (Primary Contact), Charles K. Westbrook, Marco Mehl, Mani Sarathy

Lawrence Livermore National Laboratory

P. O. Box 808, L-372

Livermore, CA 94551

Phone: (925-422-7730)

E-mail: pitz1@llnl.gov

DOE Technology Development Manager: Gurpreet Singh

Phone: (202- 586-2333); E-mail: gurpreet.singh@ee.doe.gov

\section{Objectives}

- Develop detailed chemical kinetic models for fuel components used in surrogate fuels for diesel and HCCI engines

- Develop surrogate fuel models to represent real fuels and model low temperature combustion strategies in HCCI and diesel engines that lead to low emissions and high efficiency

- Characterize the role of fuel composition on low temperature combustion modes of advanced combustion engines

\section{Accomplishments}

- Developed first-ever primary reference fuel mechanism for gasoline and diesel fuels

- Development of a high and low temperature mechanisms for series of iso-alkanes that covers the entire distillation range of diesel fuel

- Successfully simulated intermediate temperature heat release, which plays an important role in maintaining HCCI operation as the boost pressure is increased

- Developed improved mechanisms for fuel components in gasoline fuels: toluene, pentenes, and hexenes.

- Developed a functional-group kinetics modeling approach for n-alkanes that greatly reduces the size of the mechanism for use in multidimensional engine simulations

\section{Future Directions}

- Develop chemical kinetic model for a high molecular-weight aromatic to represent the aromatics chemical class in diesel fuel

- Development of low and high temperature mechanisms for a new series of isoalkanes to represent the iso-alkane chemical class in diesel fuel

- Test surrogate mixture models for gasoline by comparison to HCCI engine and RCM experiments

- Validate the chemical kinetic mechanism of 2-methyl heptane, a model iso-alkane

- Develop a functional group method for iso-alkanes in diesel fuel so that the chemical kinetic mechanism can be greatly reduced in size for multidimensional engine simulations

\section{$\underline{\text { Introduction }}$}


Predictive engine simulation models are needed to make rapid progress towards DOE's goals of increasing combustion engine efficiency and reducing pollutant emissions. These engine simulation models require chemical kinetic submodels to allow the prediction of the effect of fuel composition on engine performance and emissions. Chemical kinetic models for conventional and next-generation transportation fuels need to be developed so that engine simulation tools can predict fuel effects.

\section{$\underline{\text { Approach }}$}

Gasoline and diesel fuels consist of complex mixtures of hundreds of different components. These components can be grouped into chemical classes including n-alkanes, iso-alkanes, cycloalkanes, alkenes, oxygenates, and aromatics. Since chemical kinetic models cannot be developed for hundreds of components, specific components need to be identified to represent each of these chemical classes. Then detailed chemical kinetic models for these selected components can be developed. These component models are subsequently merged to produce a "surrogate" fuel model for gasoline, diesel, and next-generation transportation fuels. This approach can create realistic surrogates for gasoline or diesel fuels that reproduce experimental behavior of the practical real fuels. Detailed kinetic models for surrogate fuels can then be simplified as needed for inclusion in multidimensional CFD models or used in full detail for purely kinetic modeling.

\section{Results}

Iso-alkanes are present in diesel fuel in large concentrations [1] and are a chemical class that needs to be represented in a diesel surrogate model. During FY 2010, we have developed a chemical kinetic model for a whole series of iso-alkanes that covers the full distillation range of diesel fuel. It is important to represent the full distillation range in diesel to describe the complex behavior in evaporating and reacting diesel sprays. Ra et al. [2] have shown that lighter components are present in higher concentrations upstream in a simulated diesel spray and heavier components downstream. We have selected a series of 2-methyl alkanes as a starting point to represent the iso-alkanes in diesel fuel. We have developed a chemical kinetic model for all the 2-methyl alkanes from C8 to C20 to cover the full distillation range. This was a very ambitious task, involving the estimation of thermodynamic properties for thousands of species and the assembly of thousands of reactions with their associated rate constants. Subsequently, we have obtained experimental data on one of the 2-methyl alkanes (2-methyl heptane) to help validate our chemical kinetic model [3]. Predictions of the model compare well with species concentration profiles measured in a counterflow diffusion flame for 2-methyl heptane. Further experimental validations are planned.

The interesting behavior of ignition of these iso-alkanes compared n-alkanes is given in Fig. 1. The iso-alkanes are more resistant to ignition then the n-alkanes as shown by their longer ignition delay times. Also, the iso-alkanes show less low temperature chemistry in the n-alkanes because the ignition delays are particularly longer temperature range 750 to $900 \mathrm{~K}$. This is a critical temperature region for cetane number and these results indicate that the cetane numbers should be smaller for iso-alkanes compared to n-alkanes with the same carbon number which is consistent with available experimental information for cetane numbers [4]. Also Fig. 1 shows the expected trend in ignition behavior with increasing carbon number for both the n-alkanes and iso-alkanes: as the carbon number of the alkane increases, the ignition delay time decreases. This trend is particularly apparent in the negative temperature coefficient region, a key region that influences fuel effects in diesel and gasoline engines. 
Primary Reference Fuels (PRFs) are important for rating the ignition behavior of gasoline and diesel fuels. Detailed chemical kinetic models for primary reference fuels are needed to provide a reference point for comparison of the behavior of conventional and next-generation fuels. For the first time, we have developed a chemical kinetic mechanism for gasoline and diesel PRFs [5]. For gasoline PRFs, the mechanism describes the ignition of n-heptane and isooctane used to rate gasoline properties through the octane number. For diesel PRFs, our mechanism also describes the ignition of n-hexadecane and 2,2,4,4,6,8,8-heptamethylnonane used to rate diesel fuels through the cetane number test. The predicted ignition behavior of gasoline and diesel PRFs are shown in Figs 2 and 3. Predictions for the gasoline PRFs compare well with the experimental data from [6]. This mechanism provides engine designers and fuel scientists with a predictive tool to compare the behavior real fuels with reference fuels.

Chemical kinetic models for real fuels need to be reduced to allow their use in CFD engine simulation models. We have developed a new approach called the functional group approach, that greatly reduces the size of a chemical kinetic fuel mechanism and it's accompanying computational requirements. Each fuel molecule is divided up into function groups based on the molecular structure of fuel. Each function group is represented in the chemical kinetic mechanism with its own set of intermediate species and associated detailed chemical kinetic reactions. Once the fuel molecules have eventually been broken down into fragments of $\mathrm{C} 4$ or less, the chemical species are handled by our base C1 to C4 mechanism. In the case of n-decane (Fig. 4), the functional group approach has allowed a factor of 4 reduction in the number of species in the chemical kinetic model compared to a fully detailed approach. In the case of nhexadecane, the number of species was reduced by factor of 10 , greatly reducing computational requirements.

Dec et al. [7] found that intermediate temperature heat release is an important fuel behavior that allows retarded HCCI phasing and high load operation. We performed detailed kinetic modeling of intermediate temperature release and used their experimental data to provide further validation of our fuel kinetic model. We developed a methodology for formulating a gasoline surrogate model and developed a surrogate that contained n-heptane, isooctane, toluene, and 2-pentene, to simulate the 87 octane gasoline used in their experiments. As shown in Fig. 5, we were able to back predict the temperature at bottom dead center required to reproduce combustion phasing and their HCCI engine. This comparison shows that our surrogate model is able to accurately predict HCCI combustion for 87 octane gasoline. We were also able to identify the source of the intermediate temperature release which was associated with the formation of $\mathrm{HO}_{2}$ radicals and the oxidation of formaldehyde.

More accurate fuel component models are needed to formulate better surrogate models for real fuels. During FY10, we have improved our fuel component models for pentenes and hexenes to model the olefin chemical class and toluene to model the aromatic class in gasoline [8]. We have also improved the chemical kinetic model for benzene, an important intermediate in the oxidation of toluene and other aromatics. Our chemical kinetic models can now accurately predict ignition for these key gasoline components. In Fig. 6, the computed ignition delay times for toluene-air mixtures are compared to those measured over a range of temperatures and for $50 \mathrm{~atm}$, a pressure relevant to conditions in internal combustion engines.

\section{Conclusions}


- For the first time, a complete chemical kinetic mechanism for the primary reference fuels of gasoline and diesel has been developed, providing engine developers and fuel scientists with a benchmark fuel model by which other fuels are compared.

- We have assembled reaction mechanism for the high and low temperature oxidation of a series of 2-methyl alkanes that covers the entire distillation range of gasoline and diesel and can be used to represent the iso-alkane chemical class.

- A surrogate model for gasoline was developed and shown to accurately model HCCI combustion for 87 octane gasoline.

\section{Acknowledgements}

This work performed under the auspices of the U.S. Department of Energy by Lawrence Livermore National Laboratory under Contract DE-AC52-07NA27344.

\section{References}

1. W. J. Pitz and C. J. Mueller, "Recent progress in the development of diesel surrogate fuels," Progress in Energy and Combustion Science In Press, (2010).

2. Y. Ra and R. D. Reitz, "A vaporization model for discrete multi-component fuel sprays," International Journal of Multiphase Flow 35 (2) (2009) 101-117.

3. S. M. Sarathy, C. Yeung, C. K. Westbrook, W. J. Pitz, M. Mehl and M. J. Thomson, "An experimental and kinetic modeling study of n-octane and 2-methylheptane in an opposed flow diffusion flame," Combust. Flame (2011) In press.

4. M. J. Murphy, J. D. Taylor and R. L. McCormick, "Compendium of Experimental Cetane Number Data," National Renewable Energy Laboratory, NREL/SR-540-36805, www.nrel.gov/vehiclesandfuels/pdfs/sr368051.pdf (2004).

5. C. K. Westbrook, W. J. Pitz, M. Mehl and H. J. Curran, "Detailed chemical kinetic reaction mechanisms for primary reference fuels for diesel cetane number and spark-ignition octane number," Proc. Combust. Inst. In Press (2010).

6. K. Fieweger, R. Blumenthal and G. Adomeit, "Self-ignition of S.I. engine model fuels: A shock tube investigation at high pressure," Combust. Flame 109 (4) (1997) 599-619.

7. J. E. Dec and Y. Yang, "Boosted HCCI for High Power without Engine Knock and with UltraLow NOx Emissions - using Conventional Gasoline," Society of Automotive Engineers, SAE 2010-01-1086 (2010).

8. M. Mehl, W. J. Pitz, C. K. Westbrook and H. J. Curran, "Kinetic modeling of gasoline surrogate components and mixtures under engine conditions," Proc. Combust. Inst. In Press, (2010).

9. H.-P. S. Shen, J. Steinberg, J. Vanderover and M. A. Oehlschlaeger, "A Shock Tube Study of the Ignition of n-Heptane, n-Decane, n-Dodecane, and n-Tetradecane at Elevated Pressures," Energy \& Fuels 23 (5) (2009) 2482-2489.

10. U. Pfahl, K. Fieweger and G. Adomeit, "Self-Ignition of Diesel-Relevant Hydrocarbon-Air Mixtures under Engine Conditions," Proc. Combust. Inst. 26 (1996) 781-789.

11. H.-P. S. Shen, J. Vanderover and M. A. Oehlschlaeger, "A shock tube study of the autoignition of toluene/air mixtures at high pressures," Proc. Combust. Inst. 32 (1) (2009) 165-172.

\section{FY 2009 Publications/Presentations}


1. W. J. Pitz and C. J. Mueller, "Recent Progress in the Development of Diesel Surrogate

Fuels," Progress in Energy and Combustion Science (2010), in press, http://dx.doi.org/10.1016/j.pecs.2010.06.004.

2. C. K. Westbrook, W. J. Pitz, M. Mehl and H. J. Curran, "Detailed Chemical Kinetic Reaction Mechanisms for Primary Reference Fuels for Diesel Cetane Number and Spark-Ignition Octane Number," Proceedings of the Combustion Institute, 2010, in press, http://dx.doi.org/10.1016/j.proci.2010.05.087.

3. M. Mehl, W. J. Pitz, C. K. Westbrook and H. J. Curran, "Kinetic Modeling of Gasoline Surrogate Components and Mixtures under Engine Conditions," Proceedings of the Combustion Institute, 2010, in press, http://dx.doi.org/10.1016/j.proci.2010.05.027.

4. Mehl, W. J. Pitz, C. K. Westbrook, K. Yasunaga and H. J. Curran, "Autoignition behavior of unsaturated hydrocarbons in the low and high temperature regions," Proceedings of the Combustion Institute, 2010, in press. DOI: 10.1016/j.proci.2010.05.040

5. Sarathy, S. M., C. Yeung, C. K. Westbrook, W. J. Pitz, M. Mehl and M. J. Thomson (2010). "An experimental and kinetic modeling study of n-octane and 2-methylheptane in an opposed flow diffusion flame." Combustion and Flame: In press.

6. Z. Tian, W. J. Pitz, R. Fournet, P.-A. Glaude and F. Battin-Leclerc, "A detailed kinetic modeling study of toluene oxidation in a premixed laminar flame," Proceedings of the Combustion Institute, 2010, in press. DOI: 10.1016/j.proci.2010.06.063

7. M. Mehl, W. J. Pitz, C. K. Westbrook and H. J. Curran, "A functional group based kinetic model for the simulation of fuel surrogates," Spring Meeting of the Western States Section of the Combustion Institute, Boulder, CO, 2010.

8. M. Mehl, A. Frassoldati, R. Fietzek, T. Faravelli, W. J. Pitz and E. Ranzi, "Chemical kinetic study of the oxidation of toluene and related cyclic compounds," Fall Meeting of the Western States Section of the Combustion Institute, Irvine, CA, 2009.

\section{Special Recognitions \& Awards/Patents Issued}

1. Charles Westbrook: Honorary Doctorate Degree, University of Nancy, France, 2010

2. Charles Westbrook: President of the Combustion Institute

3. William J. Pitz: Best paper of the year award 2009: Combustion Society Japan

\section{Acronyms}

CFD: Computational fluid dynamics

C20: Twenty carbon atom fuel

HCCI engine: Homogeneous-charge, compression-ignition engine

SNL: Sandia National Laboratories

RCM: Rapid compression machine

PRF: Primary reference fuel

\section{Figure Captions}




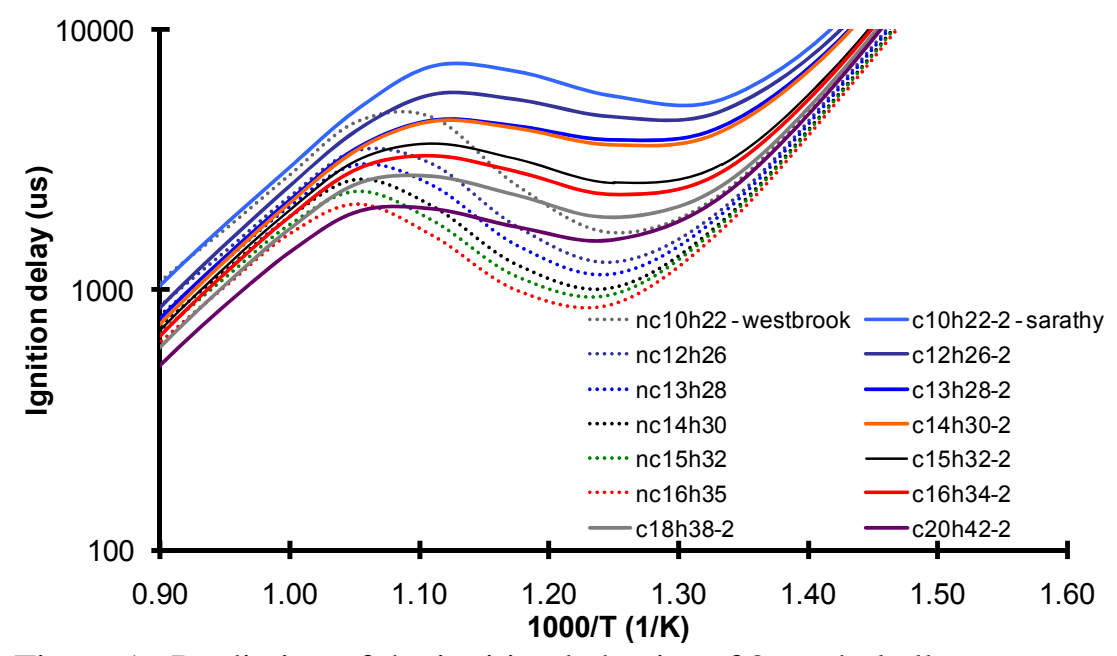

Figure 1. Prediction of the ignition behavior of 2-methyl alkanes compared to n-alkanes under representative diesel engine conditions (equivalence ratio of 3, $22 \mathrm{~atm}$, and $1.4 \%$ fuel in $\mathrm{O}_{2} / \mathrm{Ar}$ ). The region of negative slope is the negative temperature coefficient region.

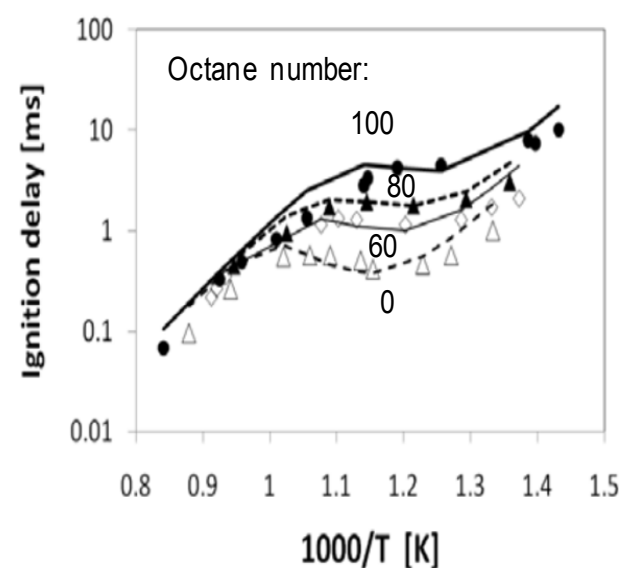

Figure 2. Computed and experimental ignition delay times for stoichiometric mixtures of gasoline PRF mixtures in air at 13 bar pressure over the low and high temperature range. (lines: predictions; symbols: experiments [6]). The numbers are the Octane numbers of the PRF mixtures. (e.g. 80 means $80 \%$ iso-octane and $20 \%$ n-heptane). 


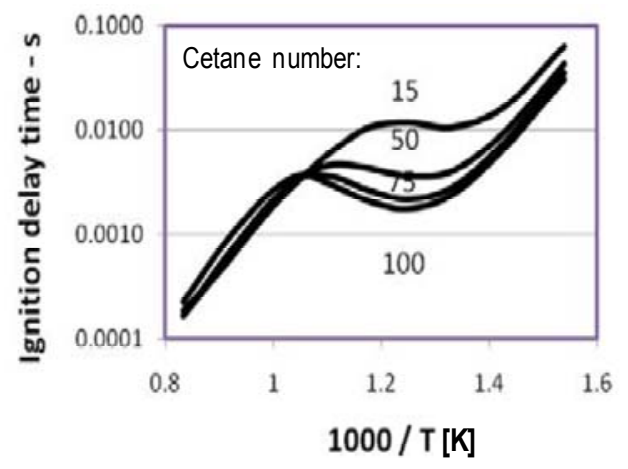

Figure 3. Computed and experimental ignition delay times for stoichiometric mixtures of gasoline PRF mixtures in air at 13 bar pressure over the low and high temperature range. (lines: predictions [5]; symbols: experiments). The numbers are the cetane numbers of the PRF mixtures.

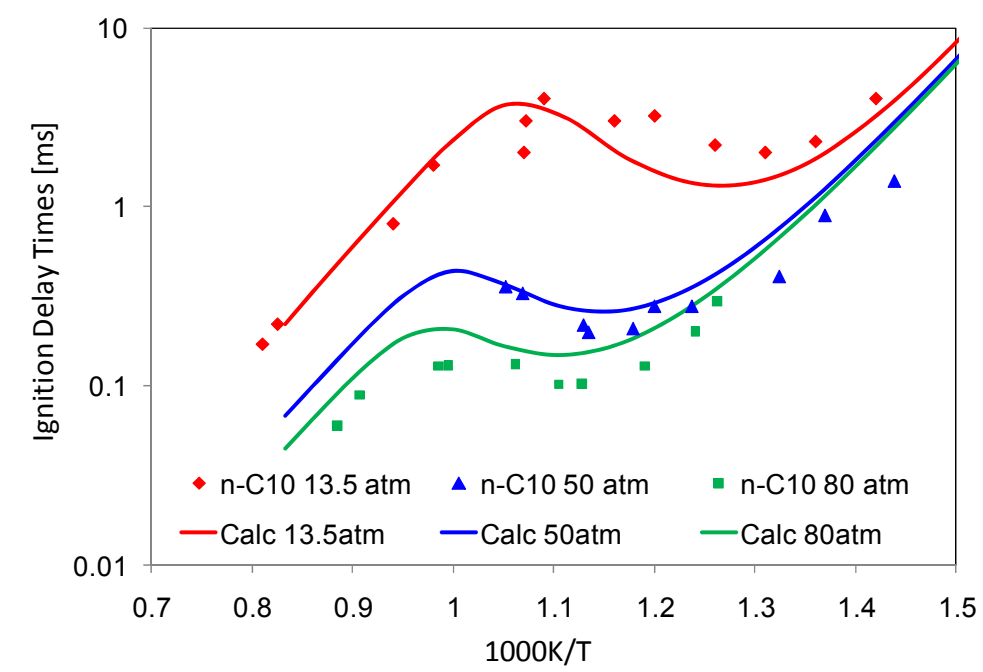

Figure 4. Ignition delay times for stoichiometric, n-decane/air mixtures, computed using a functional group approach (curves). The symbols are experimental ignition delay times from [9, 10]. 


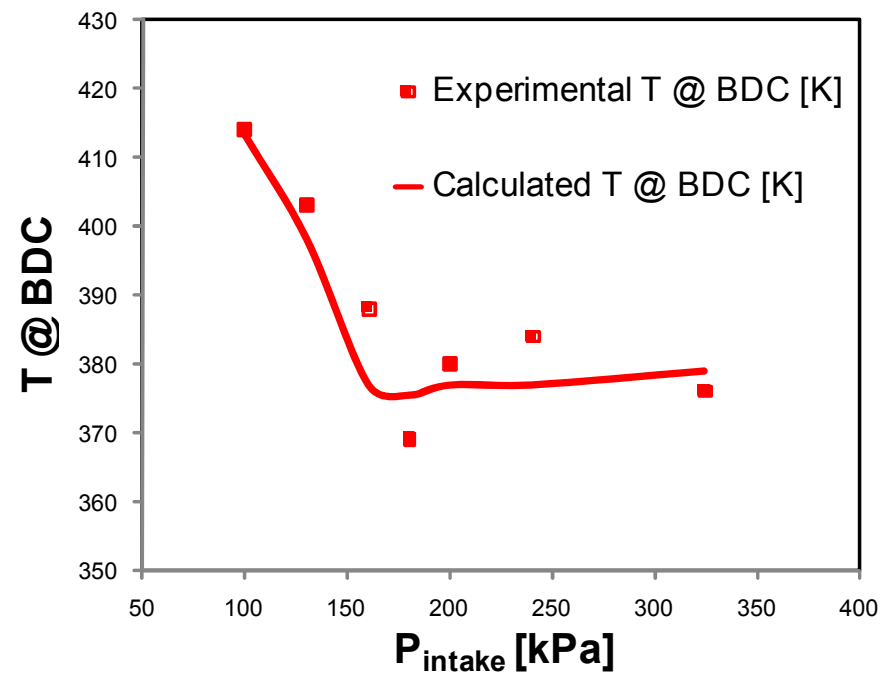

Figure 5. Gasoline surrogate model accurately back predicts bottom-dead center (BDC) temperature required to achieve SNL measured HCCI combustion timing.

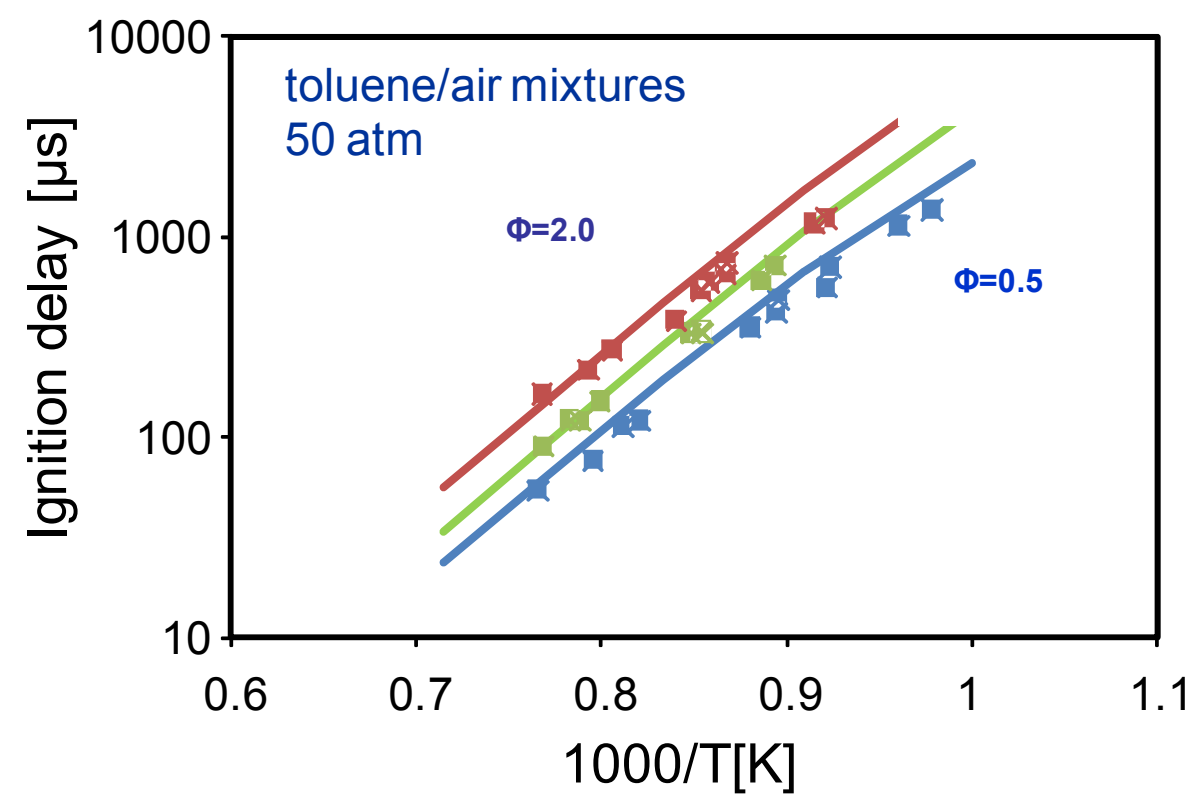

Figure 6. Computed (lines) [8] and experimental (symbols) [11] ignition delay times in a shock tube for a stoichiometric mixture of toluene in air over a range of temperatures and a pressure of $50 \mathrm{~atm}$. 